\title{
Ecdysone controlled cell and tissue deletion
}

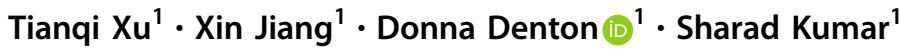

Received: 16 August 2019 / Revised: 31 October 2019 / Accepted: 4 November 2019 / Published online: 19 November 2019

(c) The Author(s), under exclusive licence to ADMC Associazione Differenziamento e Morte Cellulare 2019

\begin{abstract}
The removal of superfluous and unwanted cells is a critical part of animal development. In insects the steroid hormone ecdysone, the focus of this review, is an essential regulator of developmental transitions, including molting and metamorphosis. Like other steroid hormones, ecdysone works via nuclear hormone receptors to direct spatial and temporal regulation of gene transcription including genes required for cell death. During insect metamorphosis, pulses of ecdysone orchestrate the deletion of obsolete larval tissues, including the larval salivary glands and the midgut. In this review we discuss the molecular machinery and mechanisms of ecdysone-dependent cell and tissue removal, with a focus on studies in Drosophila and Lepidopteran insects.
\end{abstract}

\section{Facts}

- Ecdysone is a key developmental regulator in holometabolous insects that triggers the degradation and remodeling of larval tissues during metamorphosis.

- Ecdysone-mediated larval tissue deletion is spatiotemporally regulated and involves both apoptotic and autophagy-dependent cell deaths.

- Ecdysone mediates its regulatory effects via a nuclear hormone receptor complex that drives the expression of target genes directly or through ecdysone-induced transcription factors.

\section{Open questions}

- How does ecdysone trigger different spatiotemporal cell death responses during larval tissue degradation?

- What are the key features of apoptosis and autophagydependent cell death?

- Why is autophagy preferred in some circumstances over apoptosis as a cell death mediator?

Edited by E. Baehrecke

Sharad Kumar

sharad.kumar@unisa.edu.au

1 Centre for Cancer Biology, University of South Australia and SA Pathology, GPO Box 2471, Adelaide, SA 5001, Australia

\section{Introduction}

The proper development of metazoans requires a tight balance between cell death, proliferation, and differentiation [1]. Programmed cell death, defined as cell death mediated by a highly regulated genetic program, is essential for tissue patterning and deleting superfluous cells and tissues during animal development. A well-studied example of developmentally programmed cell death is tissue removal and remodeling during molting and metamorphosis of insects. The molting and metamorphosis are stimulated by secretion of ecdysteroid hormones from the prothoracic glands (PGs) [2]. During insect metamorphosis, larval tissues or entire organs can be removed by cell death as their functions are not required for adult life [3]. One of the first descriptions of developmental cell death was the degradation of insect intersegmental muscles mediated by the ecdysone pulse at the onset of metamorphosis [4]. Steroid hormone regulated cell death is not limited to insects. For example in mammals glucocorticoids are potent inducers of apoptosis in many cell types and tissues [5]. The vinegar fly, Drosophila melanogaster, with its extensively studied genetics during the past 120 years, has been widely used as a model for studying the molecular mechanisms that regulate developmental transitions including cell death. Lepidopteran insects, the butterflies and moths, have also been used to study cell death, with their large body size being an advantage for both morphological studies as well as biochemical analyses. 


\section{Cell death mechanisms regulated by ecdysone}

There are multiple ways by which animal cells can die in a regulated manner, with apoptosis being the most common one [1]. Apoptosis is a highly conserved process that is dependent on the activation of cysteine proteases, known as caspases, and features cytoplasmic condensation, nuclear fragmentation, and dismantling of cells into apoptotic bodies that are removed by phagocytosis [1]. In Drosophila there are seven caspases and while the cell death functions of all have not been fully established, they can be classified as initiator caspases (Dronc, Strica, and Dredd) and effector caspases (Drice, Dcp-1, Decay and Damm) [6-10]. Initiator caspases with long $\mathrm{N}$-terminal prodomains and their adaptors enable the formation of platforms, such as the apoptosome, that regulate their activation [7, 9, 11-15]. The adaptor protein Dark in Drosophila is required for apoptosome assembly that is essential for the activation of the initiator caspase Dronc [16]. Once activated, Dronc then cleaves effector caspases facilitating their activation. In Drosophila, activation of apoptosis is triggered by the proapoptotic proteins, Reaper (Rpr), Head involution defect (Hid), and Grim (refer to as RHG), which are upregulated by ecdysone or stress signals [17-20]. The RHG proteins act by binding to Drosophila Death-associated inhibitor of apoptosis protein 1 (Diap1), an essential caspase inhibitor, initiating autoubiquitination and degradation of Diap1, alleviating its inhibitory effects on caspases [21, 22] (Fig. 1a).

Although most cell death in animals are mediated by apoptosis, in some cases macroautophagy (referred to as autophagy) can be adapted as a mechanism of cell or tissue deletion [1]. Autophagy is an evolutionarily conserved process whereby cytoplasmic components are engulfed in a double-membrane vesicle, the autophagosome, which then fuses with the lysosome where the contents are degraded [23]. The multi-step process of autophagy is regulated by a series of Autophagy-related (Atg) proteins [24], that function in induction, nucleation, expansion and completion, then lysosomal fusion (Fig. 1b). In most cases, autophagy maintains cellular health and survival under both physiological conditions and in response to hormones, cellular stresses, including nutrient deprivation, intracellular metabolic stress, and growth factor withdrawal [25]. Moreover, depending on the context, autophagy can either cooperate with apoptosis and finalize the cell death event, or act as an independent cell death mechanism [26]. As discussed below such autophagy-dependent cell death (ADCD) is essential for the removal of larval midgut in Drosophila and is tightly regulated by ecdysone. a

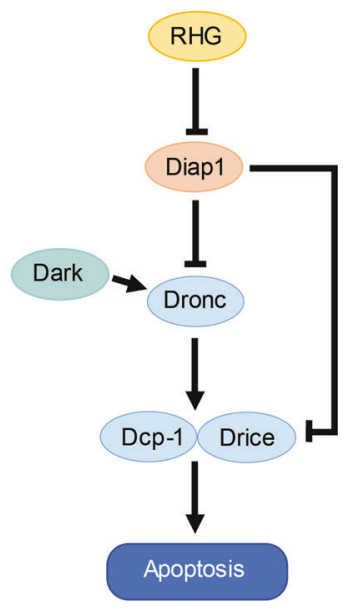

b

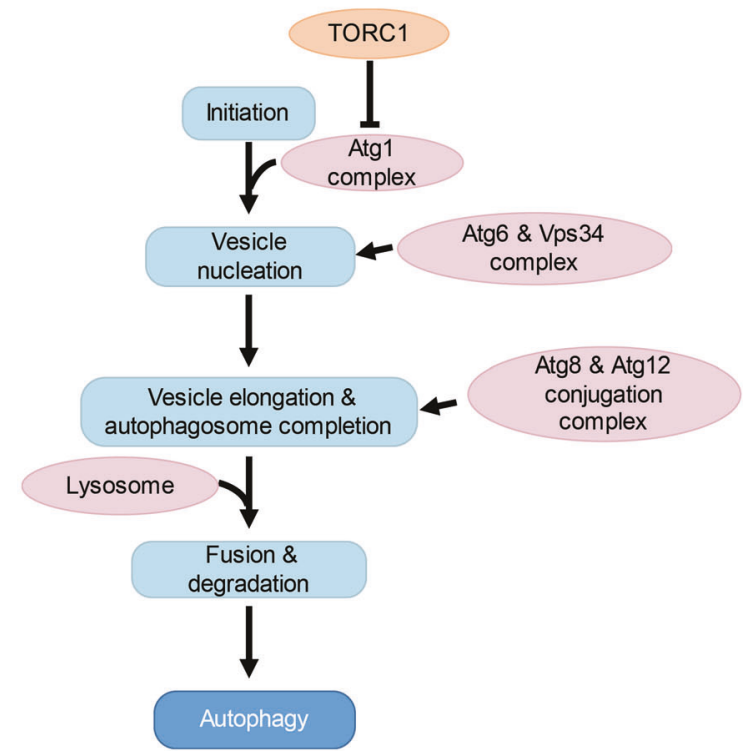

Fig. 1 Apoptosis and autophagy pathways in Drosophila. a Apoptosis: Diap1 inhibits the activation of Dronc, as well as active forms of Drice and Dcp-1, in the absence of apoptotic signals thus keeping the apoptotic machinery in check. RHG proteins (Reaper, Hid, and Grim) act as Diap1 antagonists, promoting its autoubiquitination and degradation, thus allowing Dronc activation via the Dark apoptosome. This initiates activation of downstream effector caspases Drice and Dcp-1, initiating apoptosis. b Autophagy: Target of rapamycin complex 1 (TORC1) negatively regulates autophagy by repressing Atg1, which is critical for the initiation phase of autophagy. Ecdysone signaling upregulates many of the Atg genes required for various stages of autophagy. A phagophore is formed under the regulation of Atg1 complex and Atg6 complex, which subsequently expands and matures into the autophagosome with the assistance of two ubiquitin-like conjugation systems (Atg8 and Atg12). In the final step autophagosomes fuse with the lysosomes. The luminal contents and the inner layer of the autophagosomes are degraded by lysosomal hydrolases 


\section{Ecdysone signal}

In insects, ecdysone is the central regulator of developmental transitions including molting and metamorphosis, which require tissue remodeling and removal of obsolete tissue by cell death. The biosynthesis of ecdysone occurs in the PGs [27]. Once produced from cholesterol, the precursor ecdysone is released into the hemolymph and is converted to the active form, 20-hydroxyecdysone (20E) by P450 enzymes $[28,29]$. In target cells/tissues, 20E binds to heterodimeric nuclear hormone receptors, Ecdysone receptor/ Ultraspiracle (EcR/USP), to regulate expression of genes that are responsible for physiological, morphological, and behavioral changes associated with molting and metamorphosis $[30,31]$. The term "ecdysone" has often been used as a generic name for both the precursor and the mature 20E. As the key regulator of numerous biological processes, ecdysone biogenesis in PG must be tightly regulated. Prothoracicotropic Hormone (PTTH) is a brain-derived neuropeptide that acts as the major signal for the onset of ecdysone synthesis [32, 33]. Insulin-like hormones have also been found to stimulate ecdysone secretion in the PGs of various insects [34]. In Drosophila, insulin-like peptides (dILPs) bind to insulin receptor (InR) and activate the phosphatidylinositol 3-kinase (PI3K) cascade [35]. The basal level of ecdysone biosynthesis is promoted by PI3K signaling in PG and as a negative feedback, high ecdysone levels in the fat body inhibits organismal growth [36]. As an exception, ecdysone secretion by the PG in tobacco hornworm, Manduca sexta, is not stimulated by insulin [37].

Studies in Drosophila identified three EcR isoforms (EcR-A, EcR-B1 and EcR-B2) [38, 39], with EcR-A and EcR-B1 isoforms also present in Lepidoptera including Manduca sexta and Bombyx mori [40, 41]. The isoforms of EcR result from alternative splicing and share the same DNA and ligand binding domains, with unique N-terminal $\mathrm{A} / \mathrm{B}$ domain. The isoforms are expressed in different spatial and temporal patterns [42]. The EcR-B isoforms perform an activation function whereas EcR-A has an inhibitory function in transcriptional regulation [43]. Therefore, tissues with different metamorphic responses to ecdysone express different ecdysone receptor isoforms.

\section{Ecdysone induced cell death in Drosophila}

There are three main ecdysone pulses during Drosophila metamorphosis, the late-larval, the prepupal, and the pupal pulse [44] (Fig. 2). At the transition from third instar larvae to prepupae, the degradation of larval tissues including the midgut, abdominal and anterior muscles is initiated by

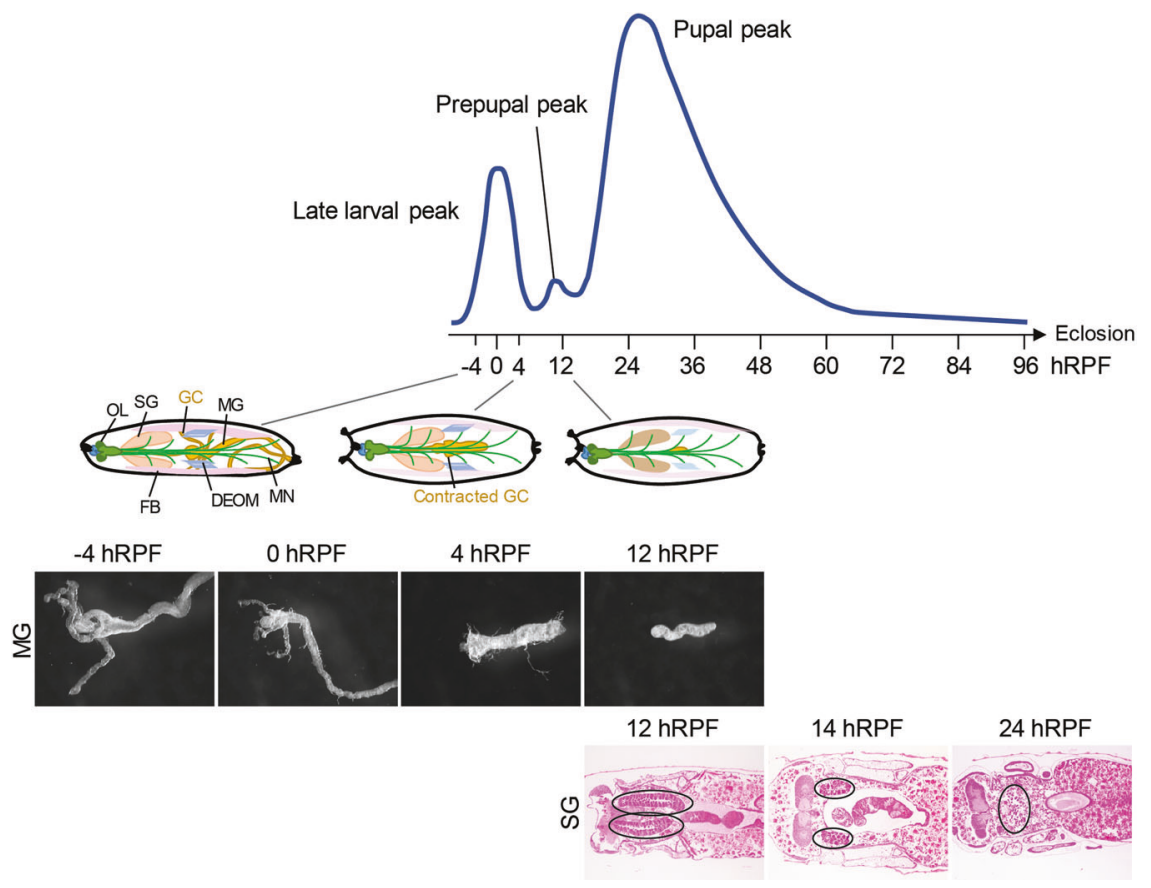

Fig. 2 Ecdysone triggers the stage-specific cell death of Drosophila larval tissues. The PG produces ecdysone. There are three ecdysone pulses that mediate metamorphosis. The late larval pulse triggers puparium formation, defining the larval-prepupal transition. The larval midgut (MG) degradation starts at $-4 \mathrm{~h}$ RPF with contraction of gastric caeca (GC) and remodeling of fat body (FB) initiates in response to this pulse. Degradation of the dorsal external oblique muscles (DEOM) occurs at 8-12 h RPF. At $12 \mathrm{~h} \mathrm{RPF,} \mathrm{the} \mathrm{larval}$ midgut condenses to form the yellow body. The prepupal ecdysone pulse triggers the prepupal to pupal transition and involves the degradation of salivary glands (SG), optic lobe (OL) and motoneurons (MN). The larval salivary glands survive the late larval ecdysone pulse but die rapidly following the prepupal pulse of ecdysone from $12 \mathrm{~h}$ RPF (circled) 
the late larvae ecdysone pulse [45-48]. The same ecdysone pulse also regulates the cell death in the optic lobe and two distinct groups of neurons in the ventral central nervous system (CNS), starting $6 \mathrm{~h}$ later relative to puparium formation (RPF) [49-51]. The prepupal pulse of ecdysone at $12 \mathrm{~h}$ RPF leads to head eversion, which marks transition to the pupal stage, and degradation of the larval salivary glands (Fig. 2) [18, 52]. This pulse of ecdysone also regulates the remodeling of neurons and the fat body during metamorphosis [53-55]. The pupal pulse that peaks about $30 \mathrm{~h}$ RPF is responsible for adult development [44] (Fig. 2). In the adult, ecdysone and nutrients coordinate cell death and enable the regular physiological function of the adult ovary [56]. We summarise below the current state of knowledge of ecdysone regulated cell and tissue degradation in Drosophila.

\section{Salivary glands}

Cell death of the Drosophila larval salivary glands has been well studied. The prepupal ecdysone pulse at $12 \mathrm{~h}$ RPF triggers the degradation of the salivary glands that are then rapidly removed by $16 \mathrm{~h}$ RPF [45, 57] (Fig. 2). The increased expression of cell death related genes, including caspases and autophagy genes, occurs in response to the increased ecdysone titre [58, 59]. Features of both apoptosis and autophagy are exhibited during salivary gland histolysis including apoptotic gene induction, enhanced caspase activity, DNA fragmentation, as well as upregulation of autophagy genes and the cytoplasmic vacuolization [58-60]. Indeed, inhibiting either apoptosis or autophagy delays the degradation of salivary glands, whilst simultaneous suppression of both autophagy and apoptosis further delays the process. This indicates that both autophagy and apoptosis are crucial for salivary gland removal $[59,60]$.

In response to the late-larval pulse, ecdysone binds to EcR/USP complex and initiates the expression of a set of primary response genes (or early puff genes) encoding transcription factors Broad-Complex (BR-C) (a zinc finger transcription factor), E74A (a ETS-domain transcription factor) and E75 (an orphan nuclear receptor) [61-65] (Fig. 3). The timing of salivary gland histolysis is tightly coordinated by the balance between cell death activators and inhibitors. For example, Diapl is actively expressed at mid-larval stage to prevent salivary gland cell death before the prepupal increase of ecdysone level [66, 67]. The latelarval ecdysone pulse activates EcR and cAMP-response element-binding protein (CBP), which is necessary and sufficient to downregulate Diapl [66, 67]. The remaining Diap1 level is sufficient to prevent early salivary glands removal until its caspase inhibitory activity is overcome by later expression of $r p r$ and hid in response to the prepupal pulse of ecdysone [66, 67] (Fig. 3). The transcription factor

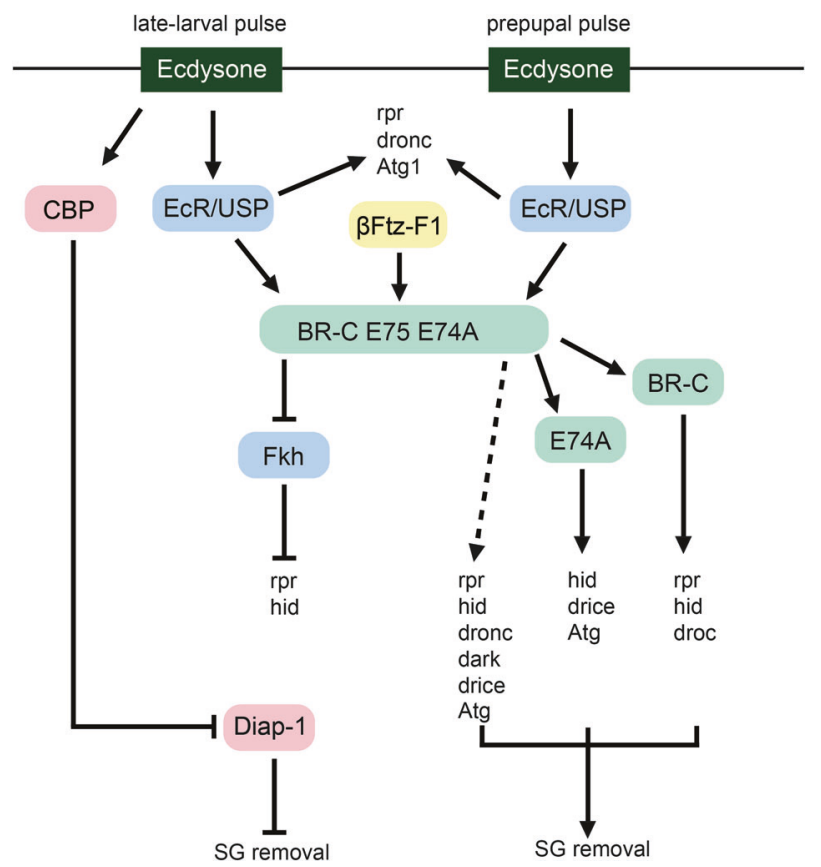

Fig. 3 Two pulses of ecdysone lead to Drosophila larval salivary gland degradation. Late larval ecdysone pulse activates EcR/USP receptor complex, which initiates the expression of primary genes $B R$ $C$, E74A, and E75. Fkh inhibits $r p r$ and hid expression prior to the prepupal ecdysone pulse. CBP downregulates Diapl expression. The remaining Diap1 prevents salivary gland from dying. The dip of ecdysone pulse after the larval stage activates $f t z-f 1$, which works together with EcR/USP regulated by the pupal stage ecdysone release to re-induce the expression of $B R-C$ and $E 74 A$. These primary response genes then initiate the expression of late genes or secondary response, promoting the transcriptions of several apoptotic and autophagic genes. EcR/USP can also directly regulate the expression of hid, rpr, dronc, and Atg1

Fork head (Fkh) inhibits $r p r$ and hid expression prior to the prepupal ecdysone pulse [68]. In response to the late-larval pulse, BR-C downregulates $F k h$. This is followed by $r p r$ and hid expression in response to prepupal pulse of ecdysone, thus driving the temporal regulation and tissue specificity of salivary gland cell death [68] (Fig. 3).

The E93 gene was previously identified as a primary response gene, encoding a large DNA binding protein that influence the transcription of secondary response genes in both salivary glands and midgut [69]. However, a more recent study demonstrated that mutant alleles of E93 used in earlier studies were in fact alleles of a nearby gene Isocitrate dehydrogenase $3 b$ (Idh3b), which encodes a key enzyme of the citric acid cycle in the mitochondria [70]. Further work will be necessary to fully resolve the controversy as to whether E93 has any role in cell death.

$\beta F T Z-F 1$, an orphan nuclear receptor, is expressed during the mid-prepupal dip in ecdysone titre and acts as a competence factor functioning together with EcR/USP complex to induce the transcription of $B R-C$ and $E 74 A$ [63, 71-73] (Fig. 3). In response to ecdysone, EcR/USP directly mediates 
the transcription of $r p r$, dronc, and Atgl by binding to their promoters $[18,74,75]$ (Fig. 3). In addition, BR-C and E74A transduce and amplify the ecdysone signal to induce cell death by regulating a group of secondary-response genes (or late puff genes) associated with both apoptosis and autophagy [18, 52, 76-82] (Fig. 3). The Drosophila H3K27me3 demethylase UTX (dUTX) interacts with EcR/USP to modulate the transcription of the apoptosis and autophagy genes, suggesting a regulatory role of epigenetic modifications in ecdysone mediated cell death [75]. As part of the secondary response, 'late' genes including pro-apoptotic genes hid, drice, and dark are upregulated, whereas Diapl is downregulated $[18,45,76-78,80]$. Expression of most of the key Atg genes is also upregulated [81-83] (Fig. 3).

Interestingly, cell death of the salivary glands involves crosstalk between layers of the ecdysone-induced transcriptional hierarchy and shows the mediation of spatially self-limiting behaviour. For instance, expression of the secondary response gene belle requires primary response genes $B R-C$ and $E 74 A$, meanwhile belle is required for proper translation of $E 74 A$ mRNA during the onset of salivary gland degradation [84, 85]. Another relatively wellcharacterised secondary response gene during salivary gland degradation is med 24 , which encodes a component of the RNA polymerase II mediator complex [85, 86]. While loss of function of med24 results in defects in amplitude of transcriptional response and a reduced rate of transcriptional initiation leading to an inhibition of caspase activation and salivary gland cell death, it does not fully block transcriptional induction of $r p r$ and hid [85-87].

Other context-specific regulators of autophagy in salivary gland cell death have been identified. MicroRNA miR-14 has been shown to regulate autophagy during salivary gland degradation through targeting inositol 1,4,5-triphosphate kinase 2 (IP3K2) activity [88]. Manipulating $m i R$-14 levels lead to a corresponding change in autophagy levels in dying salivary glands but not during starvation-induced autophagy in the fat body [88]. Loss of miR-14 does not affect EcR and BR-C during salivary gland degradation, indicating that it may act downstream of ecdysone during in salivary glands clearance [88]. While such functional specificity of miR-14 distinguishes cell death from cell survival, alternative pathways may exist to regulate salivary gland degradation in addition to ecdysone signaling. Ral, a member of the Ras superfamily of small GTPases, together with exocyst components, were also shown to be essential for autophagy in dying salivary glands but not for starvation induced autophagy in fat body [89]. Hermes, a proton-coupled pyruvate transporter, functions as a positive regulator of autophagy by inhibiting TOR in salivary glands [90].

In addition, immune signaling is also important in regulating salivary glands degradation. Studies have shown that dying salivary glands exhibit enrichment of multiple engulfment factors including immune receptor Draper (Drpr) and Croquemort (Crq) [78, 91]. Drpr presents on the surface of salivary gland cells and acts upstream of autophagy initiation in salivary gland degradation cellautonomously. This function is not observed during starvation-induced autophagy in the fat body. Loss of function mutations or knockdown of Drpr blocks salivary glands degradation and prevents autophagy initiation which can be rescued by Atgl expression in Drpr-deficient salivary glands [91]. Another regulator identified is Macroglobulin complement-related (Mcr), which acts non-cell autonomously, upstream of $\mathrm{Drpr}$ to regulate salivary gland cell death and embryonic wound healing by influencing autophagy in neighboring cells [92]. This function presents specifically in dying salivary glands, but not in the fat body under nutrient deprivation or during cell death in the midgut [92]. Moreover, the Nuclear Factor kB transcription factor Relish and the peptidoglycan recognition protein (PGRP) receptor, components of the immune deficiency pathway, are needed for autophagy in salivary gland degradation by mediating Atgl expression [93]. Transcription of crq increases in late prepupal salivary glands, immediately before the onset of cell death, possibly directly in response to primary response gene [78]. Reduced function of $\mathrm{crq}$, $d r p r$, or other genes such as simu, crq, ced-6, src42a, ced$12, c r k$, and $m b c$ involved in engulfment pathway blocks the clearance of dying salivary glands [91]. While all of this implicates a context-specific relationship between immune signaling component in mediating autophagy for cell death, the interconnection between ecdysone signaling, cell death and immune signaling needs further exploration.

Growth arrest is also important for normal degradation of larval tissues including the salivary glands and the midgut $[60,94]$. Under normal growth conditions, signaling through the insulin receptor/class I PI3K pathway and receptor tyrosine kinase via Ras/mitogen-activated protein kinase (MAPK) pathway inhibits autophagy by activating TORC1 [95]. Down regulation of these growth signals is required for autophagy-dependent cell death. Unlike in vertebrates, growth signaling suppresses cell death in salivary glands independent of FOXO [96]. Sustained growth signaling by class I PI3K pathway blocks ADCD and results in persistent salivary glands and midgut while downregulation of $\mathrm{PI} 3 \mathrm{~K}$ activity prematurely induces ADCD in these tissues [60, 94]. Thus, while there are distinct regulators of salivary gland cell death, there are similarities in the signals triggering larval midgut and salivary glands degradation.

\section{Larval midgut}

Drosophila larval midgut degradation is triggered by the late larval pulse of ecdysone [46]. The larval midgut is a 
large tissue with a proventriculus and anterior appendages called gastric caeca (GC). Initiation of midgut cell death at -4h RPF leads to contraction of proventriculus and GC, followed by midgut condensation [30, 46, 97] (Fig. 2). The adult gut starts forming $2 \mathrm{~h} \mathrm{RPF}$ encompassing the remnants of the condensed larval midgut tissue [46]. The midgut degradation has been used as a model to study ADCD [26].

Consistent with the ecdysone-mediated upregulation of cell death-related genes during salivary gland cell death, many autophagy- and apoptosis-associated genes are transcriptionally upregulated in the dying midgut. The transcription of $r p r$ and hid is increased by BR-C following the increase in ecdysone concentration, preceding both larval midgut and salivary gland cell death $[45,46]$. Other apoptotic genes such as dronc, dark, crq, and decay are all upregulated in response to increased ecdysone titre during midgut removal [46]. Coincident with the increase in ecdysone, high levels of expression of Atg genes are observed just before midgut histolysis including Atg1, Atg2, Atg3, Atg4, Atg7, Atg6, Atg8a, Atg12, and Atg18 [98]. The knockdown of $E c R$ blocks this increase in transcription of Atg genes and delays midgut removal [99]. A detailed analysis of the requirements of Atg genes in midgut degradation revealed that the autophagy machinery involved differs to that of autophagy induced in response to starvation required for cell survival. Several Atg genes in the conjugation pathway including $A \operatorname{tg} 3$ and $\operatorname{Atg} 7$ are expressed but not essential for ADCD [100, 101]. Uba1, the ubiquitin activating enzyme, is required for $\operatorname{Atg} 3$ and $\operatorname{Atg} 7$ independent autophagy and midgut degradation [101].

Surprisingly, the increased expression of apoptotic genes and caspase activity in the dying midgut is dispensable for the degradation of this tissue [98]. Blocking apoptosis by expressing the caspase inhibitor $p 35$ or by genetic ablation of multiple apoptotic genes, does not affect midgut degradation [46, 98]. In contrast, blocking autophagy delays the degradation of the midgut [98]. The combined suppression of both autophagy and caspase activity does not further delay this process compared with the inhibition of autophagy alone, suggesting that caspase activity is not required for midgut removal $[98,102]$.

Recent studies identified the Drosophila BMP/TGF- $\beta$ homologue, Decapentaplegic (Dpp), as a regulator of midgut degradation [99]. Maintained expression of Dpp supresses autophagy initiation and midgut cell death; whereas blocking Dpp signaling promotes early autophagy and rapid midgut cell death [99]. Additional studies indicate that knockdown of Tor, a key negative regulator of autophagy, can restore the block in autophagy-dependent midgut removal resulting from Dpp signaling [103]. The sustained Dpp signaling in the larval midgut also impairs the transcriptional expression of ecdysone biosynthesis genes in the PG blocking production of ecdysone [99]. This reveals that
Dpp signaling may act to coordinate ecdysone biosynthesis and developmental timing of autophagy-dependent midgut removal, possibly via TOR and other signaling pathways for mediating ecdysone-dependent cell death mechanisms. While Dpp is essential in regulating ecdysone-mediated ADCD, Hedgehog (Hh) and Wingless (Wg) signaling pathways are not involved in this process [104]. Intriguingly, the Drosophila Glycogen Synthase Kinase 3, Shaggy, a key component in $\mathrm{Hh}$ and $\mathrm{Wg}$ pathways, may act as a novel regulator of midgut cell size contraction independent of these pathways [104]. The receptor protein tyrosine phosphatase PTP52F is also required for midgut removal [105], but its role in ADCD remains unknown. It is worth noting that the destruction of midgut is delayed but not completely blocked in autophagy deficient background [98, 106]. In Dpp active midgut however, the process is completely blocked [99], suggesting that other unknown factors may be involved.

\section{Abdominal muscles}

The process of abdominal muscle histolysis is less well studied compared with larval midgut and salivary gland cell death. The degradation of the DEOMs initiates at $8 \mathrm{~h} \mathrm{RPF}$ and is completed by $12 \mathrm{~h} \mathrm{RPF} \mathrm{[107].} \mathrm{In} \mathrm{response} \mathrm{to} \mathrm{the}$ ecdysone signal through EcR-B1, destruction of DEOMs is executed solely by apoptosis, not autophagy, although the latter is also observed in degrading tissue [48, 108]. Dying DEOMs display nuclei containing condensed chromatin and muscle-specific expression of the caspase inhibitor p35 significantly inhibits active caspase staining and DEOM histolysis [48]. While blocking autophagy by knockdown of key components including Atg1, Atg5, or Atg18 shows reduced muscle autophagosome formation, it has no impact on muscle degradation [48]. Interestingly, a small subset of the abdominal muscles named the dorsal internal oblique muscles (DIOMs) are excluded from the degradation although EcR-B1 is highly expressed in DIOMs [107, 108]. The mechanism of how DIOMs evade ecdysone induced cell death remains to be further investigated.

Several nuclear proteins have been identified as regulators for DEOMs degeneration during metamorphosis. The nuclear protein Chromator promotes larval muscle histolysis whereas the nuclear protein East prevents muscle degeneration, and these antagonistic effects spatialtemporally regulate DEOMs degeneration [109]. Similarly, $\beta$ FTZ-F1, opposed by Hr39, another nuclear receptor, is critical in regulating the timing of larval muscle destruction. Knockdown of $f t z-f l$ or overexpression of $\mathrm{Hr} 39$ delays caspase activation and results in persistent DEOMs past the normal timing of removal [48]. A recent study revealed that Thin (tn), encoding a TRIM E3, acts as a novel regulator for apoptotic cell death specifically in DEOM by 
targeting Diapl [110]. Mutation of th blocks caspase-3 stanning and DEOM destruction, increases Diapl expression therefore impedes activation of Dronc independent of ecdysone signaling [110]. Nevertheless, precise mechanisms regulating integration of signals among ecdysone, these regulators, and cell death pathways remain unknown.

\section{Nervous system}

During Drosophila metamorphosis, the transformation from a crawling, feeding larva into a complex adult capable of flight and reproduction, requires a dramatic change in neurons. Previously quiescent adult-specific imaginal neurons start to develop, some neurons remodel their dendrites and axons to fit new function in the adult nervous system, some are programmed for elimination to establish a CNS as well as peripheral nervous system suitable for adult lifestyle [111].

In the CNS, the isoforms of EcR differently regulate grim and rpr expressions in different neurons to induce apoptosis $[112,113]$. In response to the late larval pulse of ecdysone, the cell death of peptidergic neurons that secrete the neuropeptide Corazonin is triggered via EcR-B1 and B2. Later after a low prepupal pulse, RP2 motorneurons in abdominal segments A2-A7 are eliminated, also requiring B isoforms of EcR [49, 51].

Cell death in the developing optic lobe occurs in two waves during metamorphosis in a unique spatio-temporal pattern triggered by ecdysone [50, 114]. EcR-B1 is expressed between 9 and $48 \mathrm{~h}$ RPF then disappears by $60 \mathrm{~h}$ RPF. EcR-A is expressed in optic lobe neurons and many types of glia from 0 to $60 \mathrm{~h} \mathrm{RPF}$ in a different pattern from EcR-B1. At $0 \mathrm{~h}$ RPF, optic lobe cell death is independent of any EcR isoforms. Two distinct clusters of cells undergo apoptosis in the lamina, most dying cells are neurons, and the others are glia. By $24 \mathrm{~h}$ RPF most cells are eliminated in the first cluster. Surprisingly, this process does not rely on EcR-B1 or A, indicating regulators other than ecdysone might be necessary [114]. From $48 \mathrm{~h}$ RPF to eclosion, a smaller number of cells are removed by apoptosis. EcR-B1 is required for the ecdysone signal transduction in optic lobe in the later cluster [50].

Although not a classical cell death event, the neuronal remodeling is an important process for the nervous system during metamorphosis [54]. In Drosophila, the dendritic arborisation (da) sensory neurons, Class IV (ddaC) neurons, larval motoneurons, mushroom body (MB) neurons, and FMR Famide expressing thoracic ventral neurons go through remodeling in response to the prepupal ecdysone pulse. The ecdysone signal upregulates soxl4 and headcase (hac) expression via EcR-B1/USP and triggers apoptotic cell death in ddaC neurons [53,115, 116]. Similar to cell death in salivary glands and midgut, the elimination of $\mathrm{MB}$ neuroblasts at the end of neurogenesis requires autophagy. Ecdysone downregulates PI3K via E93 at late pupal stage to activate autophagy [117]. Interestingly, while ecdysone triggers apoptosis in the neurons, it is also responsible for the survival of nerve cord type II neurons during metamorphosis. These neurons survive until eclosion and undergo repaid degeneration with reduced ecdysone level $[112,118]$.

\section{Fat body}

The Drosophila larval fat body undergoes remodeling during metamorphosis in response to ecdysone. Fat body cells disassociate from a single layer of cells to become individual cells, these cells are then removed at early adulthood [55, 119]. Following the ecdysone pulse at the larval-prepupal transition, fat body remodeling requires E74 for the induction of both autophagy and apoptosis genes, whereas BR-C induces apoptosis but not autophagy [120]. The remodeling is achieved mainly by autophagy, which initiates upon downregulation of PI3K [121, 122]. Although caspase activity is elevated, it does not lead to classical cellular features of apoptosis [122]. Inhibiting apoptosis or autophagy leads to upregulation of the other pathway and pupal lethality, indicating a balanced level between apoptosis and autophagy is important for normal remodeling of fat body [122].

\section{Ovary}

The ovaries are the main ecdysone production site in adult fly, although the exact mechanism of ecdysone synthesis remains unclear [123]. The structural and functional units of the ovary are the egg chambers, which consist of germline cysts and somatic follicle cells. Oogenesis is a 14 stage process that involves the moving of egg chambers out through the germarium. One of the sixteen germline cells in the germline cyst differentiates into an oocyte and the others become nurse cells [56]. The germline cell death occurs at three stages of egg chamber development, at stage $2 b$ in the germarium before the formation of follicle cell layer, at stages 7-9 in pre-vitellogenic mid-stages, and stages 12-14. Progression through the middle stage of oogenesis requires ecdysone. When the females are challenged by factors such as nutrient deprivation, extreme temperature, or chemical expose, the ovarian level of ecdysone is reduced [124]. Injecting ecdysone into diapaused females results in more chambers progressing to next stage [124]. The cell death in germline cells induced by nutrient deprivation in this oogenesis stage requires Dcp-1 and can be repressed by apoptosis inhibitor Diap1, however the exact cell death mechanisms in different cell types remain unclear [125]. Ecdysone signaling through EcR-B1 is required for the survival of the nurse and folicle cells until late oogenesis 
[126]. At the end of oogenesis, nurse cells "dump" their cytoplasmic contents into the oocyte and undergo cell death [127]. To date, the mechanism of this cell death remains unclear as it is not prevented by blocking apoptosis or autophagy [127]. The follicle cells also undergo death, in some cases this is via apoptosis [128]. As reviewed elsewhere there are additional cell death events in ovary that are not regulated by ecdysone [129].

\section{Ecdysone induced cell death in Lepidoptera}

During metamorphosis of Lepidopteran insects ecdysone signaling also regulates cell death and autophagy. Due to a large body size for morphological analysis and the available biological background information, studies using Lepidoptera have been crucial for the understanding of endocrine regulation of animal physiology (Fig. 4). However, due to limited genetic tools compared with Drosophila, much less is known about the molecular mechanisms of ecdysone dependent cell death in Lepidoptera. Here we describe studies involving specific tissue degradation in various Lepidoptera.

\section{Wings}

In Lepidoptera, several species of moths have wingless females whereas males of the same species have functional wings. This sex-specific wing degeneration occurs in females of Geometridae, Lymantriidae, Noctuidae, Psychidae, and some other families. The acquisition of wings is a key innovation that may have enabled the extreme diversification of insects. Various lines of evidence indicate that this process is controlled by ecdysone [130].

In the tussock moth (Orgyia recens), ecdysone results in the degeneration of cultured pupal female wings to about $20 \%$ of original size with apoptosis throughout the wing. Whereas male wings cultured with ecdysone show apoptosis and signs of degeneration only at the border of the

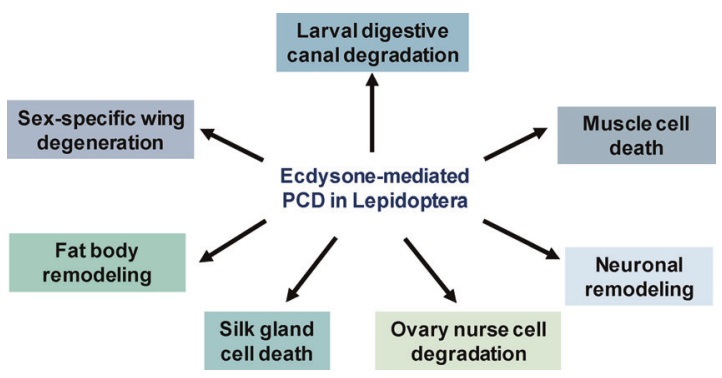

Fig. 4 Ecdysone regulated cell death in Lepidoptera. Ecdysone signaling plays critical roles in mediating diverse cell death processes during metamorphosis in lepidopteran insects, including the sexspecific wing degeneration, larval midgut histolysis, segment-specific cell death in neuronal remodeling, DEO1 muscle degradation, silk gland cell death, and fat body remodeling developing wing [131]. Injection of winter moth (Nyssiodes lefuarius) pupae with ecdysone terminates the summer diapause and triggers selective cell death in the wings of female pupae. The cell death in female pupal wings has many biological characteristics of apoptosis and autophagic cell death [130]. An earlier in vitro study shows that wing degeneration can be induced by ecdysone in silkworm (Bombyx mori) [132]. However, the exact molecular mechanism of how ecdysone regulates cell death and the pathway mediating cell death is not clear.

\section{Digestive canal}

The larval digestive canal goes through degeneration or remodeling during metamorphosis in Lepidoptera. Commencing at the last (fifth) larval instar, the Bombyx mori midgut and hindgut cells undergo a complex remodeling process involving degeneration. In response to ecdysone, autophagy is activated in the whole digestive canal at the beginning of metamorphosis, followed by apoptosis activation $[133,134]$. The ecdysone regulatory cascade in the larval midgut of the Bombyx mori required for degradation is somewhat similar to that in Drosophila. EcR-B1 and USP-1 are detected in cells undergoing death, and early response genes $E 74 B, E 75 B$, and $B R-C Z 2$ are involved in preparatory phase of cell death. It is likely that $\beta F T Z-F 1$, E74A, and BR-C Z1 are also associated with cell death [133]. Key Atg genes including BmATG5, BmATG6, and $B m A T G 8$ are highly expressed at the late larval stage [135]. Interestingly however, unlike Drosophila, a pro-survival role of autophagy was found in the Bombyx mori midgut [136]. Similarly, the woolly pyrol moth (Anticarsia gemmatalis) hindgut and midgut show signs of both apoptosis and autophagy [137]. Whereas, tobacco budworm (Heliothis virescens) midgut degradation displays characteristics of autophagy in a large majority of cells with only a limited number of cells showing apoptotic features [138]. In the cotton bollworm (Helicoverpa armigera) larval midgut, Atg12 depletion blocks both ecdysone-induced autophagy and apoptosis [139]. Compared with Drosophila larval midgut degradation where cell death is apoptosis independent, Lepidoptera digestive canal cell death appears to be more complicated as it integrates different cell death mechanisms. There is still a substantial gap in our knowledge regarding the secondary response genes and the molecular pathway in Lepidoptera midgut cell death.

\section{Neurons}

Similar to Drosophila, in Manduca sexta, ecdysone controls the cell death of extra neurons not needed in the adult [140]. The larval abdominal motoneurons undergo a segmentspecific pattern of autophagic cell death directly and cell 
autonomously in response to prepupal and pupal pulses of ecdysone [141, 142]. Due to the relatively limited genetic tools in Manduca, the cell death events in these neurons are not well-characterised. The segment-specific cell death in larval accessory planta retractor (APR) motoneurons is triggered in response to the prepupal peak of ecdysone [143]. At the end of pupal stage, reduced levels of ecdysone trigger cell death of the remaining APRs [144]. Compared with Drosophila neurons which undergo apoptosis, morphological analysis indicates that these cell death in APR neurons have autophagic features [145], but the exact molecular mechanism remains to be discovered. In Bombyx mori, neurons in the lateral portions of the brain undergo apoptosis during metamorphosis [146].

\section{Muscles}

In Manduca sexta larvae, the major muscle group across eight abdominal segments named intersegmental muscles undergoes cell death during metamorphosis. The temporal and spatial patterning of EcR-A and EcR-B1 isoforms in the dorsal external oblique 1 (DEO1) muscle corresponds with the developmental fates of the muscle fibres. Compared with Drosophila DEOM degradation which occurs relatively fast, Manduca muscle degradation occurs in a more temporal and spatial order. Shortly after pupation, in the first two anterior and first two posterior segments, muscle fibres with low levels of expression of both EcR-A and B1 undergo cell death. In response to decreased ecdysone level in the four middle segments apoptosis is induced in muscle fibres with only EcR-A just before pupal ecdysis [147, 148]. Despite the temporal and spatial differences, once cell death is initiated, similar molecular mechanisms are used in Manduca and Drosophila [147].

\section{Fat body}

Similar to Drosophila the Lepidopteran fat body undergoes extensive ecdysone-dependent remodeling. In vitro studies have shown that 20E upregulates Atg genes to induce autophagy in the Bombyx mori fat body [149]. In Manduca sexta, during fat body remodeling there are no morphological features of apoptosis or evidence of caspases upregulation [150], suggesting that apoptosis may be dispensable for fat body remodeling. This is distinct from Drosophila as the remodeling of Drosophila fat body requires both apoptosis and autophagy.

\section{Silk gland}

The silk gland in many Lepidopteran is a specialised larval tissue, most well-know in the silkworm Bombyx mori for silk production. Shortly after pupation ecdysone triggers cell death of the anterior silk glands of Bombyx mori. EcRB1 level increases at late larval stage in the silk gland to enhance the death signal transduction to the silk glands [151]. Both autophagy and apoptosis are apparent in degrading silk glands. While autophagy occurs from late larval stage for several days and progressively digests silk gland cells, apoptosis is only switched on at prepupal stage, which is the late stage of silk gland degradation [152]. The main early and late ecdysone response genes involved in Bombyx mori are similar to those in Drosophila, with differential gene expression controlling the timing of autophagy and apoptosis. Expression of $B m E c R, B m E 74 A$, $B m E 75 C$, and $B m B R-C$ are proposed to lead to autophagy, whereas BmBFTZ-F1, BmHR39, and BmE75B increase the expression of caspases, such as BmCaspase-C, and are required for apoptosis initiation [153].

\section{Ovary}

Oogenesis in Bombyx mori is a complex process involving pre-vitellogenesis (stage 1-3), vitellogenesis (stage 4-10), and choriogenesis (stage 11-12) [154]. Unlike the Drosophila ovary where ecdysone primarily function to protect cells from premature death, in Bombyx mori ovary, ecdysone induces expression of $B m E 75, B m H R 3$, and $B m B R-C$, and apoptosis and autophagy operate synergistically for the clearance of the degenerated nurse cell [155]. At stage 6, the nurse cells start morphological changes and decrease in size. At stage 7, caspase activity and autophagy can be observed in nurse cells. Later at stage 8 and 9, features of apoptosis such as chromatin condensation, DNA fragmentation can be observed [156].

\section{Conclusions}

Insects provide unique and useful models for studying in vivo functions of steroid hormones in various biological processes. In the context of developmental cell death, the removal and remodeling of tissues during insect metamorphosis have been used as models for understanding hormone regulated cell death. Given the tight spatial and temporal nature of ecdysone-mediated responses, including cell death, these models, especially the degradation of larval midgut and salivary glands in Drosophila, have provided critical insights into transcriptional control of cell death. It is interesting that ecdysone-mediated transcription controls not only the genes of the apoptotic machinery, but also autophagy where this process has been adapted for tissue deletion, such as in the Drosophila midgut. This regulation of two different types of cell death by ecdysone suggests that the one of the roles of ecdysone in metamorphosis is the removal and remodeling of larval tissues. Recent studies on 
the crosstalk between Drosophila Dpp, a morphogen of the BMP family, and ecdysone suggests that these two are crucial mediators of inter-organ signaling, including that required for spatial and temporal control of tissue deletion. Further studies in this important area of biology will no doubt shed further light into the intricacies of hormonal signaling during animal development.

Acknowledgements The Drosophila work in our group has been supported by the National Health and Medical Research Council (NHMRC) of Australia Project Grant (1124490), an Australian Research Council (ARC) Discovery Grant (DP170100623) and a NHMRC Senior Principal Research Fellowship (1103006).

\section{Compliance with ethical standards}

Conflict of interest The authors declare that they have no conflict of interest.

Publisher's note Springer Nature remains neutral with regard to jurisdictional claims in published maps and institutional affiliations.

\section{References}

1. Galluzzi L, Vitale I, Aaronson SA, Abrams JM, Adam D, Agostinis P, et al. Molecular mechanisms of cell death: recommendations of the Nomenclature Committee on Cell Death 2018. Cell Death Differ. 2018;25:486-541.

2. Thummel CS. Molecular mechanisms of developmental timing in C. elegans and Drosophila. Dev Cell. 2001;1:453-65.

3. Arya R, White K. Cell death in development: signaling pathways and core mechanisms. Semin Cell Dev Biol. 2015;39:12-9.

4. Lockshin RA, Williams CM. Programmed cell death-I. Cytology of degeneration in the intersegmental muscles of the Pernyi silkmoth. J Insect Physiol. 1965;11:123-33.

5. Vegliante R, Ciriolo MR. Autophagy and autophagic cell death: uncovering new mechanisms whereby dehydroepiandrosterone promotes beneficial effects on human health. Vitam Horm. 2018;108:273-307.

6. Kumar S, Doumanis J. The fly caspases. Cell Death Differ. 2000;7:1039.

7. Dorstyn L, Colussi PA, Quinn LM, Richardson H, Kumar S. DRONC, an ecdysone-inducible Drosophila caspase. Proc Natl Acad Sci USA. 1999;96:4307-12.

8. Xu D, Wang Y, Willecke R, Chen Z, Ding T, Bergmann A. The effector caspases drICE and dcp-1 have partially overlapping functions in the apoptotic pathway in Drosophila. Cell Death Differ. 2006;13:1697.

9. Fraser AG, Evan GI. Identification of a Drosophila melanogaster ICE/CED-3-related protease, drICE. EMBO J. 1997;16:2805-13.

10. Mills K, Daish T, Kumar S. The function of the Drosophila caspase DRONC in cell death and development. Cell Cycle. 2005;4:744-6.

11. Chen P, Rodriguez A, Erskine R, Thach T, Abrams JM. Dredd, a novel effector of the apoptosis activatorsreaper, grim, and hid in Drosophila. Dev Biol. 1998;201:202-16.

12. Dorstyn L, Read SH, Quinn LM, Richardson H, Kumar S. DECAY, a novel Drosophila caspase related to mammalian caspase-3 and caspase-7. J Biol Chem. 1999;274:30778-83.

13. Doumanis J, Quinn L, Richardson H, Kumar S. STRICA, a novel Drosophila melanogaster caspase with an unusual serine/ threonine-rich prodomain, interacts with DIAP1 and DIAP2. Cell Death Differ 2001;8:387.

14. Song Z, McCall K. Steller H. DCP-1, a Drosophila cell death protease essential for development. Science. 1997;275:536-40.

15. Harvey NL, Daish T, Mills K, Dorstyn L, Quinn LM, Read SH, et al. Characterization of the Drosophila caspase, DAMM. J Biol Chem. 2001;276:25342-50.

16. Yu X, Wang L, Acehan D, Wang X, Akey CW. Threedimensional structure of a double apoptosome formed by the Drosophila Apaf-1 related killer. J Mol Biol. 2006;355:577-89.

17. Wing JP, Schwartz LM, Nambu JR. The RHG motifs of Drosophila Reaper and Grim are important for their distinct cell death-inducing abilities. Mech Dev. 2001;102:193-203.

18. Jiang C, Lamblin AF, Steller H, Thummel CS. A steroidtriggered transcriptional hierarchy controls salivary gland cell death during Drosophila metamorphosis. Mol Cell. 2000;5: $445-55$.

19. Happo L, Strasser A, Cory S. BH3-only proteins in apoptosis at a glance. J Cell Sci. 2012;125:1081-7.

20. White K, Grether ME, Abrams JM, Young L, Farrell K, Steller H. Genetic control of programmed cell death in Drosophila. Science. 1994;264:677-83.

21. Yoo SJ, Huh JR, Muro I, Yu H, Wang L, Wang SL, et al. Hid, Rpr and Grim negatively regulate DIAP1 levels through distinct mechanisms. Nat Cell Biol. 2002;4:416.

22. Wilson R, Goyal L, Ditzel M, Zachariou A, Baker DA, Agapite $\mathrm{J}$, et al. The DIAP1 RING finger mediates ubiquitination of Dronc and is indispensable for regulating apoptosis. Nat Cell Biol. 2002;4:445.

23. He C, Klionsky DJ. Regulation mechanisms and signaling pathways of autophagy. Annu Rev Genet. 2009;43:67-93.

24. Chang YY, Neufeld TP. Autophagy takes flight in Drosophila. FEBS Lett. 2010;584:1342-9.

25. Lum JJ, DeBerardinis RJ, Thompson CB. Autophagy in metazoans: cell survival in the land of plenty. Nat Rev Mol Cell Biol. 2005;6:439-48.

26. Denton D, Kumar S. Autophagy-dependent cell death. Cell Death Differ. 2019;26:605-16.

27. Yamanaka N, Rewitz KF, O'Connor MB. Ecdysone control of developmental transitions: lessons from Drosophila research. Annu Rev Entomol. 2013;58:497-516.

28. Huang X, Warren JT, Gilbert LI. New players in the regulation of ecdysone biosynthesis. J Genet Genom. 2008;35:1-10.

29. Petryk A, Warren JT, Marques G, Jarcho MP, Gilbert LI, Kahler $\mathrm{J}$, et al. Shade is the Drosophila P450 enzyme that mediates the hydroxylation of ecdysone to the steroid insect molting hormone 20-hydroxyecdysone. Proc Natl Acad Sci USA. 2003;100: 13773-8.

30. Nicolson S, Denton D, Kumar S. Ecdysone-mediated programmed cell death in Drosophila. Int J Dev Biol. 2015;59:23-32.

31. Yao TP, Segraves WA, Oro AE, McKeown M, Evans RM. Drosophila ultraspiracle modulates ecdysone receptor function via heterodimer formation. Cell. 1992;71:63-72.

32. Kawakami A, Kataoka H, Oka T, Mizoguchi A, KimuraKawakami M, Adachi T, et al. Molecular cloning of the Bombyx mori prothoracicotropic hormone. Science. 1990;247:1333-5.

33. Niwa YS, Niwa R. Transcriptional regulation of insect steroid hormone biosynthesis and its role in controlling timing of molting and metamorphosis. Dev Growth Differ. 2016;58:94-105.

34. Smith WA, Lamattina A, Collins M. Insulin signaling pathways in lepidopteran ecdysone secretion. Front Physiol. 2014;5:19.

35. Britton JS, Lockwood WK, Li L, Cohen SM, Edgar BA. Drosophila's insulin/PI3-kinase pathway coordinates cellular metabolism with nutritional conditions. Dev Cell. 2002;2:239-49.

36. Colombani J, Bianchini L, Layalle S, Pondeville E, DauphinVillemant C, Antoniewski C, et al. Antagonistic actions of 
ecdysone and insulins determine final size in Drosophila. Science. 2005;310:667-70.

37. Walsh AL, Smith WA. Nutritional sensitivity of fifth instar prothoracic glands in the tobacco hornworm, Manduca sexta. J Insect Physiol. 2011;57:809-18.

38. Talbot WS, Swyryd EA, Hogness DS. Drosophila tissues with different metamorphic responses to ecdysone express different ecdysone receptor isoforms. Cell. 1993;73:1323-37.

39. Fujiwara H, Jindra M, Newitt R, Palli SR, Hiruma K, Riddiford LM. Cloning of an ecdysone receptor homolog from Manduca sexta and the developmental profile of its mRNA in wings. Insect Biochem Mol Biol. 1995;25:845-56.

40. Jindra M, Malone F, Hiruma K, Riddiford LM. Developmental profiles and ecdysteroid regulation of the mRNAs for two ecdysone receptor isoforms in the epidermis and wings of the tobacco hornworm, Manduca sexta. Dev Biol. 1996;180:258-72.

41. Swevers L, Cherbas L, Cherbas P, Iatrou K. Bombyx EcR (BmEcR) and Bombyx USP (BmCF1) combine to form a functional ecdysone receptor. Insect Biochem Mol Biol. 1996;26:217-21.

42. Truman JW, Talbot WS, Fahrbach SE, Hogness DS. Ecdysone receptor expression in the CNS correlates with stage-specific responses to ecdysteroids during Drosophila and Manduca development. Development. 1994;120:219-34.

43. Mouillet JF, Henrich VC, Lezzi M, Vogtli M. Differential control of gene activity by isoforms A, B1 and B2 of the Drosophila ecdysone receptor. Eur J Biochem. 2001;268:1811-9.

44. Riddiford LM. Hormone receptors and the regulation of insect metamorphosis. Receptor. 1993;3:203-9.

45. Jiang C, Baehrecke EH, Thummel CS. Steroid regulated programmed cell death during Drosophila metamorphosis. Development. 1997;124:4673-83.

46. Lee CY, Cooksey BA, Baehrecke EH. Steroid regulation of midgut cell death during Drosophila development. Dev Biol. 2002;250:101-11.

47. Neuman SD, Ihry RJ, Gruetzmacher KM, Bashirullah A. INO80dependent regression of ecdysone-induced transcriptional responses regulates developmental timing in Drosophila. Dev Biol. 2014;387:229-39.

48. Zirin J, Cheng D, Dhanyasi N, Cho J, Dura J-M, VijayRaghavan $\mathrm{K}$, et al. Ecdysone signaling at metamorphosis triggers apoptosis of Drosophila abdominal muscles. Dev Biol. 2013;383:275-84.

49. Choi YJ, Lee G, Park JH. Programmed cell death mechanisms of identifiable peptidergic neurons in Drosophila melanogaster. Development. 2006;133:2223-32.

50. Hara Y, Hirai K, Togane Y, Akagawa H, Iwabuchi K, Tsujimura $\mathrm{H}$. Ecdysone-dependent and ecdysone-independent programmed cell death in the developing optic lobe of Drosophila. Dev Biol. 2013;374:127-41.

51. Winbush A, Weeks JC. Steroid-triggered, cell-autonomous death of a Drosophila motoneuron during metamorphosis. Neural Dev 2011;6:15.

52. Lee CY, Simon CR, Woodard CT, Baehrecke EH. Genetic mechanism for the stage- and tissue-specific regulation of steroid triggered programmed cell death in Drosophila. Dev Biol. 2002;252:138-48.

53. Lee T, Marticke S, Sung C, Robinow S, Luo L. Cell-autonomous requirement of the USP/EcR-B ecdysone receptor for mushroom body neuronal remodeling in Drosophila. Neuron. 2000;28:807-18.

54. Williams DW, Truman JW. Remodeling dendrites during insect metamorphosis. J Neurobiol. 2005;64:24-33.

55. Nelliot A, Bond N, Hoshizaki DK. Fat-body remodeling in Drosophila melanogaster. Genesis. 2006;44:396-400.

56. Pritchett TL, Tanner EA, McCall K. Cracking open cell death in the Drosophila ovary. Apoptosis. 2009;14:969-79.
57. Lee C-Y, Simon CR, Woodard CT, Baehrecke EH. Genetic mechanism for the stage-and tissue-specific regulation of steroid triggered programmed cell death in Drosophila. Dev Biol. 2002;252:138-48.

58. Lee C-Y, Baehrecke EH. Steroid regulation of autophagic programmed cell death during development. Development. 2001;128: 1443-55.

59. Martin DN, Baehrecke EH. Caspases function in autophagic programmed cell death in Drosophila. Development. 2004;131: 275-84.

60. Berry DL, Baehrecke EH. Growth arrest and autophagy are required for salivary gland cell degradation in Drosophila. Cell. 2007;131:1137-48.

61. DiBello P, Withers D, Bayer C, Fristrom J, Guild G. The Drosophila Broad-Complex encodes a family of related proteins containing zinc fingers. Genetics. 1991;129:385-97.

62. Burtis KC, Thummel CS, Jones CW, Karim FD, Hogness DS. The Drosophila 74EF early puff contains E74, a complex ecdysone-inducible gene that encodes two ets-related proteins. Cell. 1990;61:85-99.

63. Baehrecke EH, Thummel CS. The Drosophila E93 gene from the $93 \mathrm{~F}$ early puff displays stage-and tissue-specific regulation by 20-hydroxyecdysone. Dev Biol. 1995;171:85-97.

64. Russell S, Ashburner M. Ecdysone-regulated chromosome puffing in Drosophila melanogaster. Metamorphosis: Postembryonic Reprogramming of Gene Expression in Amphibian and Insect Cells. Gilbert LI, Tata JR, and Atkinson BG, eds. Academic Press, NY. 1996;109-44.

65. Segraves WA, Hogness DS. development. The E75 ecdysoneinducible gene responsible for the 75B early puff in Drosophila encodes two new members of the steroid receptor superfamily. Genes Dev. 1990;4:204-19.

66. Yin VP, Thummel CS, Bashirullah A. Down-regulation of inhibitor of apoptosis levels provides competence for steroidtriggered cell death. J Cell Biol. 2007;178:85-92.

67. Yin VP, Thummel CS. A balance between the diap1 death inhibitor and reaper and hid death inducers controls steroidtriggered cell death in Drosophila. Proc Natl Acad Sci USA. 2004;101:8022-7.

68. Cao C, Liu Y, Lehmann M. Fork head controls the timing and tissue selectivity of steroid-induced developmental cell death. J Cell Biol. 2007;176:843-52.

69. Baehrecke EH, Thummel CS. The Drosophila E93 gene from the 93F early puff displays stage- and tissue-specific regulation by 20-hydroxyecdysone. Dev Biol. 1995;171:85-97.

70. Duncan DM, Kiefel P, Duncan I. Mutants for drosophila isocitrate dehydrogenase $3 \mathrm{~b}$ are defective in mitochondrial function and larval cell death. G3. 2017;7:789-99.

71. Broadus J, McCabe JR, Endrizzi B, Thummel CS, Woodard CT. The Drosophila $\beta$ FTZ-F1 orphan nuclear receptor provides competence for stage-specific responses to the steroid hormone ecdysone. Mol Cell. 1999;3:143-9.

72. Woodard CT, Baehrecke EH, Thummel CS. A molecular mechanism for the stage specificity of the Drosophila prepupal genetic response to ecdysone. Cells. 1994;79:607-16.

73. Lavorgna G, Karim FD, Thummel CS, Wu C. Potential role for a FTZ-F1 steroid receptor superfamily member in the control of Drosophila metamorphosis. Proc Natl Acad Sci USA. 1993;90: 3004-8.

74. Cakouros D, Daish TJ, Kumar S. Ecdysone receptor directly binds the promoter of the Drosophila caspase dronc, regulating its expression in specific tissues. J Cell Biol. 2004;165:631-40.

75. Denton D, Aung-Htut MT, Lorensuhewa N, Nicolson S, Zhu W, Mills K, et al. UTX coordinates steroid hormone-mediated autophagy and cell death. Nat Commun. 2013;4:2916. 
76. Cakouros D, Daish T, Martin D, Baehrecke EH, Kumar S. Ecdysone-induced expression of the caspase DRONC during hormone-dependent programmed cell death in Drosophila is regulated by Broad-Complex. J Cell Biol. 2002;157:985-96.

77. Kilpatrick ZE, Cakouros D, Kumar S. Ecdysone-mediated upregulation of the effector caspase DRICE is required for hormone-dependent apoptosis in Drosophila cells. J Biol Chem. 2005;280:11981-6.

78. Lee C-Y, Wendel DP, Reid P, Lam G, Thummel CS, Baehrecke EH. E93 directs steroid-triggered programmed cell death in Drosophila. Mol Cell. 2000;6:433-43.

79. Denton D, Aung-Htut MT, Kumar S. Developmentally programmed cell death in Drosophila. Biochim Biophys Acta. 2013;1833:3499-506.

80. Mills K, Daish T, Harvey KF, Pfleger CM, Hariharan IK, Kumar S. The Drosophila melanogaster Apaf-1 homologue ARK is required for most, but not all, programmed cell death. J Cell Biol. 2006;172:809-15.

81. Gorski SM, Chittaranjan S, Pleasance ED, Freeman J, Anderson CL, Varhol RJ, et al. A SAGE approach to discovery of genes involved in autophagic cell death. Curr Biol. 2003;13:358-63.

82. Martin D, Balgley B, Dutta S, Chen J, Rudnick P, Cranford J, et al. Proteomic analysis of steroid-triggered autophagic programmed cell death during Drosophila development. Cell Death Differ. 2007;14:916.

83. Lee C-Y, Clough EA, Yellon P, Teslovich TM, Stephan DA, Baehrecke EH. Genome-wide analyses of steroid-and radiationtriggered programmed cell death in Drosophila. Curr Biol. 2003;13:350-7.

84. Ihry RJ, Sapiro AL, Bashirullah A. Translational control by the DEAD Box RNA helicase belle regulates ecdysone-triggered transcriptional cascades. PLoS Genet. 2012;8:e1003085.

85. Ihry RJ, Bashirullah A. Genetic control of specificity to steroidtriggered responses in Drosophila. Genetics. 2014;196:767-80.

86. Wang L, Evans J, Andrews HK, Beckstead RB, Thummel CS, Bashirullah A. A genetic screen identifies new regulators of steroid-triggered programmed cell death in Drosophila. Genetics. 2008;180:269-81.

87. Wang L, Lam G, Thummel CS. Med24 and Mdh2 are required for Drosophila larval salivary gland cell death. Dev Dyn. 2010;239:954-64.

88. Nelson C, Ambros V, Baehrecke EH. miR-14 regulates autophagy during developmental cell death by targeting ip3-kinase 2 . Mol Cell. 2014;56:376-88.

89. Tracy K, Velentzas PD, Baehrecke EH. Ral GTPase and the exocyst regulate autophagy in a tissue-specific manner. EMBO Rep. 2016;17:110-21.

90. Velentzas PD, Zhang L, Das G, Chang T-K, Nelson C, Kobertz $\mathrm{WR}$, et al. The proton-coupled monocarboxylate transporter hermes is necessary for autophagy during cell death. Dev Cell. 2018;47:e4.

91. McPhee CK, Logan MA, Freeman MR, Baehrecke EH. Activation of autophagy during cell death requires the engulfment receptor Draper. Nature. 2010;465:1093.

92. Lin L, Rodrigues FS, Kary C, Contet A, Logan M, Baxter RH. et al. Complement-related regulatesautophagy in neighboring cells. Cell.2017;170:e8

93. Nandy A, Lin L, Velentzas PD, Wu LP, Baehrecke EH, Silverman NJCr. The NF- $\kappa B$ factor relish regulates Atg1 expression and controls. Autophagy. 2018;25:2110-20. e3.

94. Denton D, Chang TK, Nicolson S, Shravage B, Simin R, Baehrecke EH, et al. Relationship between growth arrest and autophagy in midgut programmed cell death in Drosophila. Cell Death Differ. 2012;19:1299-307.

95. Saxton RA, Sabatini DM. mTOR signaling in growth, metabolism, and disease. Cell. 2017;169:361-71.
96. Liu Y, Lehmann M. FOXO-independent suppression of programmed cell death by the PI3K/Akt signaling pathway in Drosophila. Dev Genes Evol. 2006;216:531-5.

97. Denton D, Mills K, Kumar S. Methods and protocols for studying cell death in Drosophila. Methods Enzymol. 2008;446:17-37.

98. Denton D, Shravage B, Simin R, Mills K, Berry DL, Baehrecke $\mathrm{EH}$, et al. Autophagy, not apoptosis, is essential for midgut cell death in Drosophila. Curr Biol. 2009;19:1741-6.

99. Denton D, Xu T, Dayan S, Nicolson S, Kumar S. Dpp regulates autophagy-dependent midgut removal and signals to block ecdysone production. Cell Death Differ. 2018;26:763-78.

100. Xu T, Nicolson S, Denton D, Kumar S. Distinct requirements of Autophagy-related genes in programmed cell death. Cell Death Differ. 2015;22:1792-802.

101. Chang TK, Shravage BV, Hayes SD, Powers CM, Simin RT, Wade Harper $J$, et al. Ubal functions in Atg7- and Atg3independent autophagy. Nat Cell Biol. 2013;15:1067-78.

102. Denton D, Shravage BV, Simin R, Baehrecke EH, Kumar S. Larval midgut destruction in Drosophila: not dependent on caspases but suppressed by the loss of autophagy. Autophagy. 2010;6:163-5.

103. Denton D, Xu T, Dayan S, Nicolson S, Kumar S. Crosstalk between Dpp and Tor signaling coordinates autophagydependent midgut degradation. Cell Death Dis. 2019;10:111.

104. Xu T, Denton D, Kumar S. Hedgehog and Wingless signaling are not essential for autophagy-dependent cell death. Biochem Pharm. 2019;162:3-13.

105. Santhanam A, Peng W-H, Yu Y-T, Sang T-K, Chen G-C, Meng T-C. Ecdysone-induced receptor tyrosine phosphatase PTP52F regulates Drosophila midgut histolysis by enhancement of autophagy and apoptosis. Mol Cell Biol. 2014;34:1594-606.

106. Xu T, Nicolson S, Denton D, Kumar S Distinct requirements of Autophagy-related genes in programmed cell death. Cell Death Differ. 2015;22:1792-802.

107. Zirin J, Nieuwenhuis J, Perrimon N. Role of autophagy in glycogen breakdown and its relevance to chloroquine myopathy. PLoS Biol. 2013;11:e1001708.

108. Kimura KI, Truman JW. Postmetamorphic cell death in the nervous and muscular systems of Drosophila melanogaster. J Neurosci. 1990;10:403-1.

109. Wasser M, Osman ZB, Chia W. EAST and Chromator control the destruction and remodeling of muscles during Drosophila metamorphosis. Dev Biol. 2007;307:380-93.

110. Vishal K, Bawa S, Brooks D, Bauman K, Geisbrecht ER. Thin is required for cell death in the Drosophila abdominal muscles by targeting DIAP1. Cell Death Dis. 2018;9:740.

111. Lee T, Lee A, Luo L. Development of the Drosophila mushroom bodies: sequential generation of three distinct types of neurons from a neuroblast. Development. 1999;126:4065-76.

112. Robinow S, Draizen TA, Truman JW. Genes that induce apoptosis: transcriptional regulation in identified, doomed neurons of the Drosophila CNS. Dev Biol. 1997;190:206-13.

113. Draizen TA, Ewer J, Robinow S. Genetic and hormonal regulation of the death of peptidergic neurons in the Drosophila central nervous system. J Neurobiol. 1999;38:455-65.

114. Togane Y, Ayukawa R, Hara Y, Akagawa H, Iwabuchi K, Tsujimura H. Spatio-temporal pattern of programmed cell death in the developing Drosophila optic lobe. Dev Growth Differ. 2012;54:503-18.

115. Kirilly D, Gu Y, Huang Y, Wu Z, Bashirullah A, Low BC, et al. A genetic pathway composed of Sox14 and Mical governs severing of dendrites during pruning. Nat Neurosci. 2009;12: 1497-505.

116. Loncle N, Williams DW. An interaction screen identifies headcase as a regulator of large-scale pruning. J Neurosci. 2012;32: 17086-96. 
117. Pahl MC, Doyle SE, Siegrist SE. E93 integrates neuroblast intrinsic state with developmental time to terminate MB neurogenesis via autophagy. Curr Biol. 2019;29:750-62.e3.

118. Robinow S, Talbot WS, Hogness DS, Truman JW. Programmed cell death in the Drosophila CNS is ecdysone-regulated and coupled with a specific ecdysone receptor isoform. Development. 1993;119:1251-9.

119. Aguila JR, Suszko J, Gibbs AG, Hoshizaki DK. The role of larval fat cells in adult Drosophila melanogaster. J Exp Biol. 2007;210:956-63.

120. Liu H, Wang J, Li S. E93 predominantly transduces 20hydroxyecdysone signaling to induce autophagy and caspase activity in Drosophila fat body. Insect Biochem Mol Biol. 2014:45:30-9.

121. Lindmo K, Simonsen A, Brech A, Finley K, Rusten TE, Stenmark H. A dual function for Deep orange in programmed autophagy in the Drosophila melanogaster fat body. Exp Cell Res. 2006;312:2018-27.

122. Liu H, Jia Q, Tettamanti G, Li S. Balancing crosstalk between 20-hydroxyecdysone-induced autophagy and caspase activity in the fat body during Drosophila larval-prepupal transition. Insect Biochem Mol Biol. 2013;43:1068-78.

123. Terashima J, Takaki K, Sakurai S, Bownes M. Nutritional status affects 20-hydroxyecdysone concentration and progression of oogenesis in Drosophila melanogaster. J Endocrinol. 2005;187: 69-79.

124. Richard DS, Gilbert M, Crum B, Hollinshead DM, Schelble S, Scheswohl D. Yolk protein endocytosis by oocytes in Drosophila melanogaster: immunofluorescent localization of clathrin, adaptin and the yolk protein receptor. J Insect Physiol. 2001;47:715-23.

125. Laundrie B, Peterson JS, Baum JS, Chang JC, Fileppo D, Thompson SR, et al. Germline cell death is inhibited by Pelement insertions disrupting the dcp-1/pita nested gene pair in Drosophila. Genetics. 2003;165:1881-8.

126. Buszczak M, Freeman MR, Carlson JR, Bender M, Cooley L, Segraves WA. Ecdysone response genes govern egg chamber development during mid-oogenesis in Drosophila. Development. 1999;126:4581-9.

127. Yalonetskaya A, Mondragon AA, Elguero J, McCall KI. Spy in the developing fly a multitude of ways to die. J Dev Biol. 2018;6:26.

128. Borensztejn A, Boissoneau E, Fernandez G, Agnes F, Pret AM. JAK/STAT autocontrol of ligand-producing cell number through apoptosis. Development. 2013;140:195-204.

129. Jenkins VK, Timmons AK, McCall K. Diversity of cell death pathways: insight from the fly ovary. Trends Cell Biol. 2013;23: 567-74.

130. Niitsu S, Toga K, Tomizuka S, Maekawa K, Machida R, Kamito T. Ecdysteroid-induced programmed cell death is essential for sex-specific wing degeneration of the wingless-female winter moth. PLoS One. 2014;9:e89435.

131. Lobbia S, Niitsu S, Fujiwara H. Female-specific wing degeneration caused by ecdysteroid in the Tussock Moth, Orgyia recens: hormonal and developmental regulation of sexual dimorphism. J Insect Sci. 2003;3:11.

132. Fujiwara H, Ogai S. Ecdysteroid-induced programmed cell death and cell proliferation during pupal wing development of the silkworm, Bombyx mori. Dev Genes Evol. 2001;211:118-23.

133. Goncu E, Uranli R, Selek G, Parlak O. Developmental expression of ecdysone-related genes associated with metamorphic changes during midgut remodeling of silkworm Bombyx mori (Lepidoptera:Bombycidae). J Insect Sci. 2016;16:86.

134. Romanelli D, Casartelli M, Cappellozza S, de Eguileor M, Tettamanti G. Roles and regulation of autophagy and apoptosis in the remodelling of the lepidopteran midgut epithelium during metamorphosis. Sci Rep. 2016;6:32939.
135. Franzetti E, Huang ZJ, Shi YX, Xie K, Deng XJ, Li JP, et al. Autophagy precedes apoptosis during the remodeling of silkworm larval midgut. Apoptosis. 2012;17:305-24.

136. Franzetti E, Casartelli M, D’Antona P, Montali A, Romanelli D, Cappellozza S, et al. Midgut epithelium in molting silkworm: a fine balance among cell growth, differentiation, and survival. Arthropod Struct Dev. 2016;45:368-79.

137. Levy SM, Falleiros AM, Gregorio EA, Arrebola NR, Toledo LA. The larval midgut of Anticarsia gemmatalis (Hubner) (Lepidoptera: Noctuidae): light and electron microscopy studies of the epithelial cells. Braz J Biol. 2004;64:633-8.

138. Tettamanti G, Grimaldi A, Casartelli M, Ambrosetti E, Ponti B, Congiu $\mathrm{T}$, et al. Programmed cell death and stem cell differentiation are responsible for midgut replacement in Heliothis virescens during prepupal instar. Cell Tissue Res. 2007;330:345-59.

139. Li YB, Yang T, Wang JX, Zhao XF. The steroid hormone 20hydroxyecdysone regulates the conjugation of autophagy-related proteins 12 and 5 in a concentration and time-dependent manner to promote insect midgut programmed cell death. Front Endocrinol. 2018;9:28.

140. Tissot M, Stocker RF. Metamorphosis in drosophila and other insects: the fate of neurons throughout the stages. Prog Neurobiol. 2000;62:89-111.

141. Weeks JC, Ernst-Utzschneider K. Respecification of larval proleg motoneurons during metamorphosis of the tobacco hornworm, Manduca sexta: segmental dependence and hormonal regulation. J Neurobiol. 1989;20:569-92.

142. Weeks JC, Roberts WM, Trimble DL. Hormonal regulation and segmental specificity of motoneuron phenotype during metamorphosis of the tobacco hornworm, Manduca sexta. Dev Biol. 1992;149:185-96.

143. Weeks JC. Thinking globally, acting locally: steroid hormone regulation of the dendritic architecture, synaptic connectivity and death of an individual neuron. Prog Neurobiol. 2003;70:421-42.

144. Zee MC, Weeks JC. Developmental change in the steroid hormone signal for cell-autonomous, segment-specific programmed cell death of a motoneuron. Dev Biol. 2001;235:45-61.

145. Kinch G, Hoffman KL, Rodrigues EM, Zee MC, Weeks JC. Steroid-triggered programmed cell death of a motoneuron is autophagic and involves structural changes in mitochondria. $\mathbf{J}$ Comp Neurol. 2003;457:384-403.

146. Kim MY, Kim KM, Choi CO, Song HY, Lee CS, Kim BW, et al. Apoptosis of neuronal cells in the brains of postembryonic silkworms Bombyx mori (Lepidoptera: Bombycidae). Eur J Entomol. 2009;106:335-45.

147. Myer A, Mason HA, Smith W, Brown C, Schwartz LM. Differential control of cell death and gene expression during two distinct phases of hormonally-regulated muscle death in the tobacco hawkmoth Manduca sexta. J Insect Physiol. 2009;55:314-20.

148. Hegstrom CD, Truman JW. Steroid control of muscle remodeling during metamorphosis in Manduca sexta. J Neurobiol. 1996;29:535-50.

149. Tian L, Ma L, Guo E, Deng X, Ma S, Xia Q, et al. 20Hydroxyecdysone upregulates Atg genes to induce autophagy in the Bombyx fat body. Autophagy. 2013;9:1172-87.

150. Muller F, Adori C, Sass M. Autophagic and apoptotic features during programmed cell death in the fat body of the tobacco hornworm (Manduca sexta). Eur J Cell Biol. 2004;83:67-78.

151. Goncu E, Parlak O. Morphological changes and patterns of ecdysone receptor B1 immunolocalization in the anterior silk gland undergoing programmed cell death in the silkworm, Bombyx mori. Acta Histochem. 2009;111:25-34.

152. Montali A, Romanelli D, Cappellozza S, Grimaldi A, de Eguileor M, Tettamanti G. Timing of autophagy and apoptosis during posterior silk gland degeneration in Bombyx mori. Arthropod Struct Dev. 2017;46:518-28. 
153. Hu C, Zhang X, Teng YB, Hu HX, Li WF. Structure of autophagy-related protein Atg8 from the silkworm Bombyx mori. Acta Crystallogr, Sect F: Struct Biol Cryst Commun. 2010;66:787-90.

154. Yamauchi H, Yoshitake N. Developmental stages of ovarian follicles of the silkworm, Bombyx mori L. J Morphol. 1984;179: 21-31.
155. Swevers L, Iatrou K. The ecdysone regulatory cascade and ovarian development in lepidopteran insects: insights from the silkmoth paradigm. Insect Biochem Mol Biol. 2003;33: 1285-97.

156. Mpakou VE, Nezis IP, Stravopodis DJ, Margaritis LH, Papassideri IS. Different modes of programmed cell death during oogenesis of the silkmoth Bombyx mori. Autophagy. 2008;4:97-100. 